\title{
Examining the Influence of Passive Design Approaches on NZEBs: Potential Net Zero Healthcare Buildings Implementation in Malaysia
}

\author{
Roy Hazli Bin Abdellah", ${ }^{1,}$, Md Asrul Nasid Bin Masrom ${ }^{1}$, Goh Kai Chen ${ }^{1}$, Sulzakimin Mohamed ${ }^{1}$, Norpadzlihatun Manap ${ }^{1}$ \\ ${ }^{1}$ Department of Construction Management, Faculty of Technology Management and Business, Universiti Tun Hussein Onn Malaysia, \\ 86400 Parit Raja, Johor, Malaysia.
}

\begin{abstract}
Nowadays, net-zero energy buildings (NZEBs) concept has gained considerable attention not only between the developed countries, but also among the developing countries including Malaysia. The rapid development in Malaysia, especially in the construction of healthcare buildings needs to be given due attention since these developments lead to all sorts of environmental problems. As the number of healthcare buildings increases, the energy consumes to operate these buildings will increase. The consequences of uncontrollable energy consumption may result in the increased volume of carbon dioxide emissions as well as depletion of natural resources. Thus, NZEBs has emerged as a proactive concept to confront with these issues. Therefore, the purpose of this paper is to examine the influence of passive design approaches on NZEBs as well as the potential of net zero healthcare buildings implementation in Malaysia based on a review of the existing literature and by utilising semi-structured interviews with 3 experienced architects. The result of this paper indicates that there are four main passive design components has strong influences on NZEBs which are building orientation, shading devices, ventilation, and thermal insulation. These practices are being actively practiced in Malaysia construction industry; thus, it shows that net zero energy healthcare buildings are potential to be designed in Malaysia. The study has gone some way towards enhancing our understanding of the significance of passive design approaches towards net zero healthcare buildings for future implementation in Malaysia context.
\end{abstract}

\section{Introduction}

Recently, the sustainability in construction has been given a growing attention by many countries for the rapid development in the construction sector leads to major concerns on sustainability for this sector. According to Kibert [1], the construction sector must shift to a sustainable approach to overcome its adverse impact on the environment. But, this approach should require the support from the government as well as all parties who are involved in this sector [2].

In the Malaysia context, efforts and concerns towards sustainability have been shown by the Malaysian government through implementation of several national energy policies as well as the five-year Malaysian plan. For instance, the eleventh Malaysia Plan (2016-2020), the government aims to have a resilient, low carbon, resource efficiency and social inclusion kind of development. These aims show the Malaysian government commitment towards achieving sustainable development [3].

The introduction of NZEBs since 2010 has been a positive step towards achieving the sustainability in construction goals. Therefore, in the Europe, European Union Parliament regulated that all new buildings are
NZEBs in 2020 [4]. By having this regulation, the members of the European Union Parliament are progressively to define NZEBs as well as to implement this concept in their countries.

Fundamentally, NZEBs is a concept to represent a zero or low energy building by meeting the building energy demand with the utilisation of renewable energy systems installed in buildings [5]. In order words, NZEBs is defined as an energy produces from renewable energy sources is equally as it consumes in a year [6].

Concerning to design, there is still a lack of specific design guidelines to design NZEBs. But, there are some common design elements that could be taken into consideration [7]. One of the important element to design NZEBs is through passive desi fundamental requirement for net zero energy buildings [8].

Therefore, it is important to understand that passive design approaches are considered to be significant in designing net zero healthcare buildings in Malaysia. In response, the aim of this paper is to present findings based on reviewing extensive of literature as well as an exploratory study of Malaysian construction practitioners in the influence of building's passive design approaches towards the potential of net zero healthcare buildings implementation in Malaysia.

\footnotetext{
* Corresponding author: hazliroy@gmail.com
} 


\section{Literature review}

The purpose of the literature review section to provide a clear understanding on NZEBs as well as the NZEBs design in a systematic way. Previous research on NZEBs will be reviewed in this section.

\subsection{NZEBs overview}

Primarily, NZEBs, as defined by The National Renewable Energy Laboratory (NREL), consists of four main definitions which are net zero site energy, net zero source energy, net zero energy emissions, and net zero energy cost [9]. Further clarification of these definitions are as follows:

-Net Zero Source Energy - A NZEB produces at least as much energy as it uses in a year when accounted for at the source. Source energy refers to the primary energy used to generate and deliver the energy to the site.

-Net Zero Energy Costs - the amount of money the utility pays the building owner for the renewable energy the building exports to the grid is at least equal to the amount the owner pays the utility for the energy services and energy used over the year.

-Net Zero Site Energy - A site NZEB produces at least as much energy as it uses in a year when accounted for at the site.

-Net Zero Emissions - A net-zero emissions building produces at least as much emissionsfree renewable energy as it uses from emissions-producing energy sources.

However, NZEBs definition has been improvised through the study by [10] where the authors had addressed several of the criteria in the definition to provide NZEB definitions in a structured way. Some of the criteria are boundary condition, crediting system, net zero balance, temporal energy match, and monitoring procedure.

NZEBs definition has been continuously improved since 2006 up to recently. NZEBs can be understood as buildings that utilising various types of renewable sources to produce energy and its energy consumption are equal with its energy production during the period of a year.

\subsection{Designing NZEBs}

The need to identify NZEBs design approaches is important to ensure widespread use of this concept. There is a large volume of published studies describing that there are many ways and methods that can be used to design NZEBs. For instance, according to Aelenei et al., [11] studied on close inspection of the relevant design strategies and relative performance indicators of the eight case studies, the authors stated that there are no standard design guidelines for NZEBs.
However, in a study by Lu et al., [7], authors had mentioned that there are three main steps of a design approach that can be applied in designing NZEBs. he first design approach is a passive approach that focused on reducing energy demand? The second design approach is the use energy efficiency system, and the third design approach is a renewable energy system which is needed to generate renewable energy as well as to offset in large measure the energy demand. The combination of this three-design approach will increase the ability to succeed in reaching the desired energy performance as well as NZEBs target.

\begin{tabular}{|c|c|c|}
\hline $\begin{array}{c}\text { Passive } \\
\text { Approaches }\end{array}$ & $\begin{array}{l}\text { Energy } \\
\text { Efficient } \\
\text { Systems }\end{array}$ & $\begin{array}{c}\text { Renewable } \\
\text { Energy } \\
\text { Systems }\end{array}$ \\
\hline Orientation & $\begin{array}{l}\text { Energy } \\
\text { Eficient } \\
\text { Mechanical }\end{array}$ & \begin{tabular}{|l} 
Solar \\
Electric \\
PV
\end{tabular} \\
\hline $\begin{array}{l}\text { Shading } \\
\text { Devices }\end{array}$ & System & $\begin{array}{l}\text { Solar } \\
\text { Water } \\
\text { Heating }\end{array}$ \\
\hline Ventilation & $\begin{array}{l}\text { Eficient } \\
\text { Electrical } \\
\text { System }\end{array}$ & \\
\hline $\begin{array}{l}\text { Thermal } \\
\text { Insulation }\end{array}$ & & \\
\hline
\end{tabular}

Fig. 1. NZEBs main design approaches.

Therefore, by considering the NZEBs design approaches as illustrated in Fig. 1, the focus of this paper is only given towards examining the influence of passive design approaches to NZEBs.

\subsection{Passive approaches}

The passive approach integrates into the structure of the building technologies that admit, absorb, store, and release solar energy, thereby able to reduce the necessity for electricity used to transport fluids [6]. Several studies have found that passive approach is one of the important design elements for NZEBs. For instance, [12] in their study of the design of Net Zero Energy Buildings and Net Zero Energy Neighbourhoods in the future also highlighted that the passive approach plays a significant part in the NZEBs design.

Moreover, passive approaches are significant in influencing the necessity of buildings mechanical and electrical systems, as well as indirectly affect the renewable energy generation [11]. However, it is important to realise that the passive approaches involved many components such as orientation, types of shading devices, ventilation, glazing, skylights and thermal insulation. These components have a great influence on maintaining a comfortable temperature in buildings 


\subsubsection{Orientation}

The appropriate orientation in designing a building is crucial in achieving low building energy consumption by controlling what areas will be protected by direct solar radiation and those that received direct solar radiation. In the same vein, according to [13] building orientation is one of building design parameters that can be controlled in potentially reduce the energy consumption in a building and by considering the size, layout, and partition of a building. Similarly [14] stated that lower energy demand in building design can be achieved through good design of the building envelope.

Furthermore, the azimuth in the wall and the building's angle have a strong impact on the amounts of direct radiation hitting to the building. For instance, based on [15] in the study on the effects of building orientation on the energy reduction for four different types of residential buildings locating in Tehran by using the Ecotect software. The authors concluded that building orientation is one of the most important factors in determining the volume of solar energy received. Moreover, the authors also stated that the maximum level of solar radiation can be achieved by having a building facing the south, hence the maximum of lighting penetration can be gained by windows having been in the south side of the building.

In addition, one of the key benefits in properly orientating a building is that it will affect the reduction of energy consumption in a building. According to [16] in the study to investigate the impact that building orientation has on energy use by using Building Information Modelling (BIM) showed that the amount of internal solar gain depending on the interaction of building orientation with the sun, thus it will directly reduce on the number of energy needs for heating and lighting units as well as improve efficiency. Besides that, the investigation has proved that building orientation has some great impacts towards energy use in a building.

Therefore, when designing NZEBs, it is crucial to determine the optimal selection of building orientation at the designing stage of building construction since it influences the need of energy in buildings, thereby affecting the NZEBs goals.

\subsubsection{Shading devices}

The main function of a shading system is to reduce heat gain in a building by limiting the undesirable solar radiations through the transparent parts of the building into a building. Previous studies have shown that the amount of energy consumption in buildings for cooling and lighting can significantly reduce by having a suitable shading device. For instance, [17] in the study to design a fixed shading device for two climates, Trieste and Rome by performing genetic optimization (GO) on an office room with a south facing window. The findings showed that there is a $19 \%$ reduction in primary energy consumption were achieved for Trieste while $30 \%$ for Rome compared to the unshaded window.

However, it is important to realise that shading devices can be categorized into three types which are fixed shading systems, movable shading systems, and other shading systems [18]. The classification of shading systems will be illustrated as in Fig. 2. According to [19] in the study on the performance of different shading devices for the visual environment by using the RADIANCE simulation tool. The results showed that levels of desirable daylight, thermal comfort, and visual comfort will be affected by using different types of shading device.

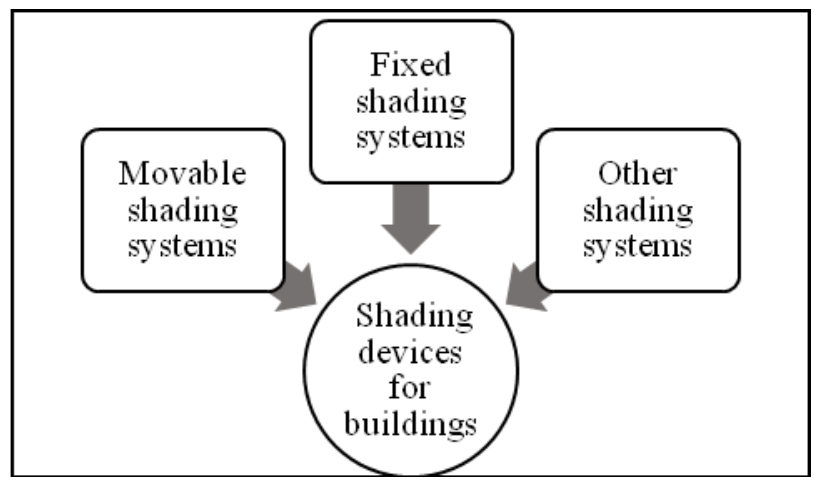

Fig. 1. Shading devices for buildings [18]

Additionally, numerous studies have reported that by having a properly designed of shading devices, it will influence the thermal performance of a building. In a study by [20] on the effects of using louvres shading devices in the building thermal performance in different cities with various latitudes and climatic conditions. It was shown that shading devices are significant towards saving energy and ensuring indoor comfortable thermal conditions as well as space cooling.

Therefore, shading device in the building envelope is able to mitigate the unnecessary solar radiations and as a result, energy needs reduction for cooling load in a building can be reached. In other words, NZEBs target in the reduction of energy demand can be achieved since this shading device able to reduce energy consumption throughout a building.

\subsubsection{Ventilation}

Generally, the basic concept of natural ventilation is to reduce heat by cooling of the building during at night while during the daytime by improving indoor thermal comfort without the need for mechanical cooling [21]. There are two driving forces to natural ventilation which are pressure differences generated by wind or/and buoyancy [22]. Besides that, designing a natural ventilation system is a complex task due to variable pressure differences, unlike with the controllable energy source used in mechanical ventilation.

Other researchers also have highlighted the importance of ventilation in passive design strategies in buildings. There are numerous numbers of benefits that can be gained through the aspect of natural ventilation in a building. For instance, natural ventilation plays an important part in the conservation of energy, carbon emission reduction, improvement of the comfort level as well as indoor air quality [23]. Moreover, natural 
ventilation is an important aspect in a passive technique that able to give impact on the reduction of building cooling energy demand as well as indoor air quality improvement. However, natural ventilation need to be designed with a deep knowledge and the prediction of airflow need to be accurate as well as heat transfer in and around buildings [24].

Regarding energy reduction, [25] in the framework study of free cooling by means of night ventilation were considered and it was selected as one of the strategies leading to primary energy reduction. The simulation study shows that the implementation of night ventilation results in a primary energy reduction for space cooling of $17 \%$ without any other mechanical assistance. According to the economic analysis, the net additional cost of such an intervention is almost zero and allows the reduction of the surface of the PV panels that are required for the attainment of net zero energy balance.

Thus, natural ventilation needs to be properly designed since it is significant to provide cooling loads into the buildings without using mechanical systems as well as it appears to energy reduction in building especially for warm and hot climates. Hence, natural ventilation is vital in a building design to achieve NZEBs goal.

\subsubsection{Thermal insulation}

The main objective of thermal insulation systems and materials in a building is to decrease the transmission of heat flow [26]. Other than that, an excellent thermal insulation material is required to produce an effective external wall and a well-insulated building envelope is a key factor to achieve higher energy-efficient performance of buildings. Moreover, a highly insulated building envelope is an important aspect of achieving NZEBs [27].

Some researchers have shown the importance of a well-designed thermal insulation of building in achieving energy saving. An experimental study carried out by [28] on the energy saving potential of thermal insulation by replacing the plywood-reinforced honeycomb sandwich panel for the conventional honeycomb sandwich panel as building materials. The results showed that the electricity consumption for a room with the walls fabricated from the Chinese plywood reinforced sandwich material is lower than the electricity consumption for a room with regular walls. Moreover, [29] carried out research on the impacts of wall insulation thickness on the annual cooling and heating energy uses under three different climates in China, which are Guangzhou, Shanghai and Beijing by introducing Energy Gain Ratio (EGR) and Relative Variation Ratio (RVR) as indexes to assess the impact. The results showed that the more percentage of energy savings of annual cooling and heating energy was achieved when insulation thickness was thicker for the exterior zones facing east under Beijing's and Shanghai's climates.

Therefore, the thermal insulation of buildings plays a significant part in reducing energy consumption as well as it helps to achieve NZEBs goals. The consideration of the thermal insulation material of a building is crucial in optimizing the energy of the building. However, some technical characteristics of building insulations should not be ignored.

\section{Research methodology}

The purpose of this section is to describe the methods that were used for this paper. The semi-structured interview has been chosen for this research since there are limited literature on the net zero healthcare buildings as well as NZEBs practices in Malaysia context. Further explanation of data collection for this paper as in subsection 3.1 .

\subsection{Data collection procedure}

The face-to-face semi-structured interview method has been carried out at places decided by the respondents, and each of the interviews has been conducted around 30 to 60 minutes. A semi-structured interview was chosen since been more flexible and less controlled, thereby it able to highlight on the influence of passive design approaches on NZEBs as well as the potential of net zero healthcare buildings implementation in Malaysia.

Furthermore, the interviewees were assigned codes as R1, R2, and R3. Besides that, to ensure the quality of the interviews, all respondents are active in the Malaysian construction industry and had direct involvement in the building projects located within Malaysia. The key profiles for the interviewees are shown in Table 1.

Table 1. Key profiles for interviewees.

\begin{tabular}{|l|l|l|l|}
\hline Table 1. Key profiles for interviewees. \\
\hline Item & R1 & R2 & R3 \\
\hline Position & Architect & Architect & Architect \\
\hline Expanization & Consultant & Consultant & $\begin{array}{l}\text { Developer } \\
/ \text { Client }\end{array}$ \\
\hline
\end{tabular}

\section{Findings and discussions}

This section examines and discusses the key findings that emerged from semi-structured interviews that were conducted. Generally, it demonstrates the influence of passive design approaches on NZEBs as well as the potential of net zero healthcare buildings implementation in Malaysia.

As discussed in the earlier literature, several studies have found that the orientation of the building is important towards reducing the energy demand in a building. Based on the interviews, all respondents also have agreed that the orientation of the building has strong impacts on the energy required for buildings. For example, interviewees R2 and R3 mentioned:

...by gaining a direct solar heat, especially in Malaysia, the occupants will feel uncomfortable and it is important for an architect to properly 
orientated a building so that some areas will be avoided by direct solar radiation. (R2)

...building orientation is the most fundamental and most easily addressed aspect to reduce the heat gain in a building. (R3)

Thus, the results of this study indicate that the orientation of the building is important, and it has a strong impact on energy use in buildings. Besides, the result further supports the idea from previous researchers that a proper and appropriate for building orientation will result in lower energy demand in the building, thus NZEBs goals could be achieved.

Regarding the potential of the net-zero energy healthcare buildings implementation in Malaysia through of building orientation aspect, some of the interviewees responded that this kind of building could be constructed in Malaysia since most of the architects in Malaysia have the knowledge of building orientation. However, one of the interviewees argued that some of the clients have their own requirements and it is quite challenging to convince the clients, thus it makes net zero healthcare buildings difficult to construct. As interviewee R1 put it:

...sometimes, when we proposed to design healthcare buildings with proper building orientation, but it has been rejected by our client. (R1)

Moreover, there is a large volume of published studies describing the role of shading devices is important towards reducing energy consumption and achieving NZEBs. For instance, Charisi [30] who studied on the effect of various parameters on the energy demand of the building to achieve NZEBs from modelling a typical Greek residential building. The authors found that the use of shading devices may lead to significant energy savings in warmer climate zones.

However, the interviewees have responded differently. The R2 interviewee has disagreed that availability of shading devices as significant as building orientation to the buildings since the availability of shading always blocks a part of the view. Besides that, Buildings need for admitting controlled levels of daylight. However, some of the interviewees agreed that the availability of shading devices is important to the buildings as it able to prevent the solar gain, thereby affecting the energy need in buildings (R1, R3). Thus, these results match those observed in earlier studies and it also indicated that shading devices have some influences on energy demand in buildings.

In addition, a considerable amount of literature has been published that shows natural ventilation is important in buildings as it improved the thermal comfort. The interviewees were asked about this aspect and all the interviewees agreed on the importance of natural ventilation in a building. As one interviewee said:

...as an architect who responsible to design a building, we have taken a serious consideration on this aspect. (R3)
Thus, these findings further support the idea from previous researchers that natural ventilation will influence the energy consumption in a building as well as occupant comfort [21]. Besides that, in accordance with the present findings, it indicates that natural ventilation has been practised in Malaysia, thereby net zero healthcare building has the potential to be designed in Malaysia.

Furthermore, several studies thus far have linked thermal insulation in buildings with energy need reduction. For instance, [31] investigated the impacts of using external wall insulation on energy consumption, and the indoor thermal environment. There are two different types of chambers were constructed which are an energy efficient chamber with thermal insulation used in the external wall, and a basic chamber based on the common design principles for residential buildings in the $1980 \mathrm{~s}$ and 1990s. The investigation concluded that energy consumption for cooling in summer can be reduced significantly by insulation used in the building envelope.

The results show that most respondents agreed that good of insulation in a building able to act as a barrier to the heat gain. Talking about this issue an interviewee said:

...we are aware of the importance of building insulation and it can be seen when the asbestos ceiling has become common materials used in building since it is fireproof as well as good thermal and electrical insulator for buildings. (R1)

As a result, these findings indicate that insulation material has a strong influence on achieving high energy-efficient performance of buildings as well as NZEBs objectives.

Table 2. Summary findings of passive design approaches

\begin{tabular}{|c|c|}
\hline $\begin{array}{c}\text { Passive Design } \\
\text { Approaches }\end{array}$ & Key points from interviewees \\
\hline $\begin{array}{c}\text { Building } \\
\text { Orientation }\end{array}$ & $\begin{array}{c}\text { "...it is undeniable that architect should } \\
\text { ensure that building orientation is } \\
\text { appropriate to achieve low energy demand." } \\
\text { (R2) }\end{array}$ \\
\hline $\begin{array}{c}\text { Shading } \\
\text { Devices }\end{array}$ & $\begin{array}{c}\text { "...although shading devices have a strong } \\
\text { impact on energy need, but the client will } \\
\text { take consideration of this aspect, and we } \\
\text { have to design a plan according to the } \\
\text { requirements." (R1) }\end{array}$ \\
\hline $\begin{array}{c}\text { Natural } \\
\text { Ventilation }\end{array}$ & $\begin{array}{c}\text { "...it is compulsory for any architect to } \\
\text { highlight on natural ventilation when } \\
\text { designing a building." (R3) }\end{array}$ \\
\hline Insulation & $\begin{array}{c}\text { "...an appropriate of insulation materials } \\
\text { should be considered and different climate, } \\
\text { require different types of insulation } \\
\text { materials." (R1) }\end{array}$ \\
\hline
\end{tabular}

\section{Conclusion and recommendation}

As a conclusion, passive design approaches show an important role towards NZEBs concept. Besides that, architects have an important role in controlling aspects 
of passive design when designing NZEBs. The findings show that passive design approaches have a strong influence towards NZEBs where building orientation, shading devices, natural ventilation, and insulation need to be considered and properly designed since it affects the energy demand as well as NZEBs objectives. These design approaches are being practised actively in Malaysia construction industry; thus, it shows that net zero energy healthcare buildings are potential to be designed in Malaysia However, it is suggested that other construction players' perspective should be included to establish a more comprehensive perspective and insight.

\section{References}

1. C. J. Kibert, Sustainable construction: green building design and delivery (John Wiley \& Sons, 2016)

2. T. H. Oh, S.Y. Pang, S. C. Chua, Renew. and Sus. Ener. Rev. 14, 4, 2010.

3. A. A. M. Bohari, M. Skitmore, B. Xia, M. Teo, X. Zhang, K.N. Adham, Renew. and Sus. Ener. Rev. 52 (2015)

4. E. P. B. D. Recast, Off. J. of the E. U. 18, 6 (2010)

5. P. Torcellini, S. Pless, C. Lobato, T. Hootman, In Proceedings of ASME. International Conference on Energy Sustainability (2010)

6. W. OBrien, A. K. Athienitis, Modeling, design, and optimization of net-zero energy buildings (Berlin: Erns \& Sohn. 2015)

7. L. Yuehong, W. Shengwei, S. Kui, App. Ener. 155 (2015)

8. T. Hootman, Net zero energy design a guide for commercial architecture (Hoboken (N.J.): J. Wiley \& Sons. 2013)

9. P. Torcellini, S. Pless, M. Deru, D. Crawley, D., Zero energy buildings: a critical look at the definition. Washington, D.C. (National Renewable Energy Laboratory and Department of Energy 2006)

10. I. Sartori, N. Assunta, V. Karsten, Ener. and Build. 48 (2012)

11. D. Aelenei, L. Aelenei, E. Musall, E. Cubi, J. Ayoub, A. Belleri, In CLIMA 2013-11th REHVA World Congress \& 8th International Conference on IAQVEC (2013)

12. A. Scognamiglio, F. Garde, H.N. Røstvik, Ener Proc., 61 (2014)

13. H. Liu, Q. Zhao, N. Huang, X. Zhao, IEEE Trans. on Auto. Sc. and Eng., 10, 1 (2013)

14. M. Ferrara, E. Fabrizio, J. Virgone, M. Filippi, Ener. Proc., 78 (2015)

15. F. Faizi, M. Noorani, A. Ghaedi, M. Mahdavinejad, Ener. Proc., 21 (2011)

16. F. H. Abanda, L. Byers, Ener., 97 (2016)

17. M. Manzan, Ener. and Build., 72 (2014)

18. L. Bellia, C. Marino, F. Minichiello, A. Pedace, Ener. Proc., 62 (2014)
19. H. S. Lim, G. Kim, In. and Built Envir., 19 (2010)

20. A. I. Palmero-Marrero, A. C. Oliveira, App. Ener., 87, 6 (2010)

21. M. Alizadeh, S. M. Sadrameli, S. M. Renew. and Sust. Ener. Rev., 58 (2016)

22. G. C. Da Graça, P. Linden, Build. and Env., 107 (2016)

23. W. Guo, X. Liu, X. Yuan, Proc. Eng., 121, (2015)

24. Z. J. Zhai, M. El Mankibi, A. Zoubir, Ener. Proc., 78 (2015)

25. G. Evola, G. Margani, L. Marletta, Ener. and Build., 68 (2014)

26. F. Asdrubali, F. D'Alessandro, S.Schiavoni, Sust. Mat. and Tech., 4, (2015)

27. T. Ojanen, I. P. Seppä, E. Nykänen, Ener. Proc., 78 (2015)

28. A. Reengwaree, V. Premanond, S. Torsakul, Ener. Proc., 34 (2013)

29. D. Pan, M. Chan, S. Deng, Z. Lin, Z. App. Ener., 97 (2012)

30. S. Charisi, Proc. Env. Sc., 38 (2017)

31. Z. Fang, N. Li, B. Li, G. Luo, Y. Huang, Ener. and Build., 77 (2014) 